have already referred to. A gloom was cast over the meeting by the announcement of the sudden death of Prof. Kolbe, the distinguished recipient of the Davy Medal.

The Annual Dinner subsequently took place at Willis's Rooms, the Treasurer being supported by the Lord Chancellor, the Marquess of Salisbury, the Lord Mayor, and others.

\section{THE WAVE THEORY OF LIGHT}

II.

TO continue our study of visible light, that is, undulations extending from red to violet in the spectrum (which I am going to show you presently), I would first point out on this chart that in the section from letter "A " to letter " $D$ " we have visual effect and heating effect only; but no ordinary chemical or photograpbic effect. Photographers can leave their usual sensitive chenically prepared plates exposed to yellow light and red light without experiencing any sensible effect; but when you get

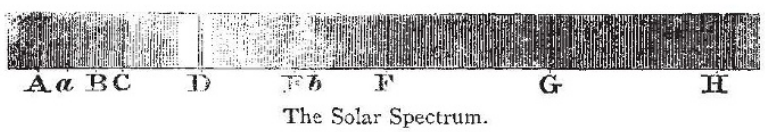

toward the blue end of the spectrum the photographic effect begins to tell, more and more as you get towards the violet end. When you get beyond the violet, there is the invisible light known chiefly by its chemical action. From yellow to violet we have visual effect, heating effect, and chemical effect, all three ; above the violet only chemical and heating effects, and so little of the heating effect that it is scarcely perceptible.

The prismatic spectrum is Newton's discovery of the composition of white light. White light consists of every variety of colour from red to violet. Here, now, we have Newton's prismatic spectrum produced by a prism. I will illustrate little in regard to the nature of colour by putting something before the light which is like coloured glass ; it is coloured gelatine. I will put in a plate of red gelatine which is carefully prepared of chemical materials, and see what that will do. Of all the light passing to it from violet to red it only lets through the red and orange, giving a mixed reddish colour.

Here is another plate of green gelatine. The green absorbs all the red, giving only green. Here is another plate absorbing something from each portion of the spectrum, taking away a great deal of the violet and giving a yellow or orange appearance to the light. Here is another absorbing out the green, leaving red, orange, and a very little faint green, and absorbing out all the violet.

When the spectrum is very carefully produced, far more perfectly than Newton knew how to show it, we have a homogeneous spectrum. It must be noticed that Newton did not understand what we call a homogeneous spectrum; he did not produce it, and does not point out in his writings the conditions for producing it. With an exceedingly fine line of light we can bring it out as in sunlight, like this upper picture, red, orange, yellow, green, blue, indigo, and violet, according to Niewton's nomenclature. Newton never used a narrow beam of light, and so could not have had a homogeneous spectrum.

This is a diagram painted on glass and showing the colours as wc know them. It would take two or three hours if I were to explain the subject of spectrum analysis to-night. We must tear ourselves away from it. I will just read out to you the wave lengths corresponding to the different positions in the sun's spectrum of certain dark lines commonly called "Fraunhofer's lines." I will take as a unit the one-hundred thou-andth of a centimetre. A centimetre is ' 4 of an inch; it is a rather small half an inch. I take the thousandth of a centimetre and the hundredth of that as a unit. At the red end of the spectrum the light in the neighbourhood of that black line " $A$ " has for its wave length 7.6 ; " $B$ " has $6.87 ;$ " $D$ " has 5.89 ; the "frequency" for " $A$ " is 3.9 times roo million million; the frequency of " $D$ " light is 5 . I times 100 million million per second.

Now what force is concerned in those vibrations as compared with sound at the rate of 400 vibrations per second; suppose for a moment the same matter was to move to and fro through

1 A Lecture delivered at the Academy of Music, Philadelphia, under the auspices of the Franklin Institute, September 29, 1884 , by Sir William Thomson, F.R.S., LL.D. (Contintied from p. 94). the same range, but 400 million million times per second. The force required is as the square of the number expressing the frequency. Double frequency would require quadruple force for the vibration of the same body. Suppose I vibrate my hand again, as I did before. If I move it once per second a moderate force is required ; for it to vibrate ten times per second roo times as much force is required ; for 400 vibrations per second 160,000 times as much force.

If I move my hand once per second through a space of a quarter of an inch a very small force is required; it would require very considerable force to move it ten times a second, even through so small a range; but think of the force required to move a tuning fork 400 times a second; compare that with the force required for a motion of 400 million million times a second. If the mass moved is the same, and the range of motion is the same, then the force would be one million million million million times as great as the force required to move the prongs of the tuning fork. It is as easy to understand that number as any number like 2,3 , or 4 .

Consider gravely what that number means and what we are to infer from it. What force is there in space between my eye and that light? What forces are there in spacs between our eyes and the sun, and our eyes and the remotest visible star? There is matter and there is motion, but what magnitude of force may there be?

I move through this "luminiferous ether" as if it were nothing. But were there vibrations with such frequency in a mediuin of steel or brass, they would be measured by millions and millions and millions of tons action on a square inch of matter. There are no such forces in our air. Comets make a disturbance in the air, and perhaps the luminiferous ether is split up by the motion of a comet through it. So when we explain the nature of electricity, we explain it by a motion of the luminiferous ether. We cannot say that it is electricity. What can this luminiferous ether be? It is something that the planets move through with the greatest ease. It permeates our air; it is nearly in the same condition, so far as our means of judging are concerned, in our air and in the inter-planetary space. The air disturbs it but little ; you may reduce air by air-pumps to the hundred-thousardth of its density, and you make little effect in the transmission of light through it. The luminiferous ether is an elastic solid. The nearest analogy I can give you is this jelly which you see. ${ }^{1}$ The nearest analogy to the waves of light is the motion, which you can imagine, of this elastic jelly, with a ball of wood floating in the middle of it. Look there, when with my hand I vibrate the little red ball up and down, or when I turn it quickly round the vertical diameter, alternately in opposite directions; - That is the nearest representation I can give you of the vibrations of luminiferous ether.

Another illustration is Scottish shoemaker's wax or Burgundy pitch, but I know Scottish shoemaker's wax better. It is heavier than water, and absolutely answers my purpose. I take a large slab of the wax, place it in a glass jar filled with water, place a number of corks on the lower side and bullets on the upper side. It is brittle like the Trinidad pitch or Burgundy pitch which I have in my hand. You can see how hard it is, but if left to itself it flows like a fluid. The shoemaker's wax breaks with a brittle fracture, but it is viscous and gradually yields.

What we know of the luminiferous ether is that it has the rigidity of a solid and gradually yields. Whether or not it is brittle and cracks we cannot yct tell, but I believe the discoveries in electricity, and the motions of comets, and the marvellous spurts of light from them, tend to show cracks in the luminiferous ethershow a correspondence between the electric flash and the aurora borealis and cracks in the luminiferous ether. Do not take this as an assertion, it is hardly more than a vague scientific dream : but you may regard the existence of the luminiferous ether as a reality of science, that is, we have an all-pervading medium, an elastic solid, with a great degree of rigidity; its rigidity is so prodigious in proportion to its density that the vibrations of light in it have the frequencies I have mentiond, with the wave lengths I have mentioned.

The fundamental question as to whether or not luminiferous ether has gravity has not been answered. We have no knowledge that the luminiferous ether is attracted by gravity; it is sometimes called imponderable because some people vainly imagine that it has no weight. I call it matter with the same kind of rigidity that this elastic jelly has.

' Exhibiting a large bowl of clear jelly with a small red wooden bal embedded in the surface near the centre. 
Here are two tourmalines; if you look through them toward the light, you see the white light all round, i.e. they are transparent. If I turn round one of these tourmalines the light is extinguished, it is absolutely black, as though the tourmalines were opaque. This is an illustration of what is called polarisation of light. I cannot speak to you about qualities of light without speaking of the polarisation of light. I want to show you a most beautiful effect of polarising light, before illlustrating a little further by means of this large mechanical illustration which you have in the bowl of jelly. Now I put in the lantern another instrument called a "Nicol prism." What you saw first were two plates of the crystal tourmaline which came from Brazil, I believe, having the property of letting light pass when both plates are placed in one particular direction as regards their axes of crystallisation, and extinguishing it when it passes through the first plate held in another direction. We have now an instrument which also gives rays of polarised light. A Nicol prism is a piece of Iceland spar, cut in two and turned, one part relatively to the other, in a very ingenious way, and put together again and cemented into one by Canada balsam. The Nicol prism takes advantage of the property which the spar has of double refraction, and produces the phenomenon which I now show you.

I turn one prism round in a certain direction and you get light, a maximum of light. I turn it through a right angle and you get blackness. I turn it one quarter round again and get maximum light; one quarter more, maximum blackness; one quarter more and bright light. We rarely have such a grand specimen of a Nicol prism as this.

There is another way of producing polarised light. I stand before that light and look at its reflection in a plate of glass on the table through one of the Nicol prisms, which I turn round, so. Now I must incline that piece of glass at a particular angle, rather more than $45^{\circ}$; I find a particular angle in which, if I look at it and then turn the prism round in the hand, the effect is absolutely to extinguish the light in one position and to give it maximum brightness in another position. I use the term "absolute" somewhat rashly. It is only a reduction to a very small quantity of light, not an absolute annulment as we have in the case of the two Nicol prisms used conjointly. Those of you who have never heard of this before would not know what I am talking about. As to the mechanics of the thing it could only be explained to you by a course of lectures in physical optics. The thing is this, vibrations of light must be in a definite direction relatively to the line in which the light travels.

Look at this diagram, the light goes from left to right; we have vibrations perpendicular to the line of transmission. There is a line up and down which is the line of vibration. Imagine here a source of light, violet light, and here in front of it is the line of propagation. Sound vibrations are to and fro; this is transverse to the line of propagation. Here is another, perpendicular to the diagram, still following the law of transverse vibration; here is another circular vibration. Imagine a long rope, you whirl one end of it and you send a screw-like motion running along ; you can get the circular motion in one direction or in the opposite.

Plane polarised light is light with the vibrations all in a single plane, perpendicular to the plane through the ray which is technically called the " plane of polarisation." Circular polarised light consists of undulations of luminiferous ether having a circular motion. Elliptically polarised light is something between the two, not in a straight line, and not in a circular line; the course of vibration is an ellipse. Polarised light is light that performs its motions continually in one mode or direction. If in a straight line it is plane polarised light; if in a circular direction it is circularly polarised light ; when elliptical it is elliptically polarised light.

With Iceland spar, one unpolarised ray of light divides on entering it into two rays of polarised light, by reason of its power of double refraction, and the vibrations are perpendicular to one another in the two emerging rays. Light is always polarised when it is reflected from a plate of unsilvered ylass, or water, at a certain definite angle of $56^{\circ}$ degrees for glass, or $52^{\circ}$ for water, the angle being reckoned in each case from a perpendicular to the surface. The angle for water is the angle whose tangent is I4. I wish you to look at the polarisation with your own eyes. Light from glass at $56^{\circ}$ and from water at $52^{\circ}$ goes away vibrating perpendicularly to the plane of incidence and plane of reflection.

We can distinguish it without the aid of an instrument. There is a phenomenon well known in physical optics as "Haidinger's
Brushes." The discoverer is well known in Philadelphia as a mineralogist, and the phenomenon I speak of goes by his name. Look at the sky in a direction of $90^{\circ}$ from the sun, and you will see a yellow and blue cross, with the yellow toward the sun, and from the sun, spreading out like two fox's tails with blue between, and then two red brushes in the space at right angles to the blue. If you do not see it, it is because your eyes are not sensitive enough, but a little training will give them the needed sensitiveness.

If you cannot see it in this way try another method. Look into a pail of water with a black bottom; or take a clear glass dish of water, rest it on a black cloth and look down at the surface of the water on a day with a white cloudy sky (if there is such a thing ever to be seen in Philadelphia). You will see the white sky reflected in the basin of water at an angle of about $50^{\circ}$. Look at it with the head tipped to one side and then again with the head tipped to the other side, keeping your eyes on the water, and you will see Haidinger's brushes. Do not do it fast or you will make yourself giddy. The explanation of this is the refreshing of the sensibility of the retina. The Haidinger's brush is always there, but you do not see it because your eye is not sensitive enough. After once seeing it you always see it; it does not thrust itself inconveniently before you when you do not want to see it. You can readily see it in a piece of glass with dark cloth below it, or in a basin of water.

I am going to conclude by telling you how we know the wave lengths of light and how we know the frequency of the vibrations. We shall actually make a measurement of the wave length of the yellow light. I am going to show you the diffraction spectrum.

You see on the screen, ${ }^{1}$ on each side of a central white bar of light, a set of bars of light variegated colours, the first one, on each side, showing blue or incligo colour about four inches from the central white bar and red about four inches farther, with vivid green between the blue and the red. That effect is produced by a grating with 400 lines to the centimetre, engraved on glass, which I now hold in my hand. The next grating has 3000 lines on a Paris inch. You see the central space and on each side a large number of spectra, blue at one end and red at the other. The fact that, in the first spectrum red is abont twice as far from the centre as the blue, proves that a wave length of red light is double that of blue light.

I will now show you the operation of measuring the length of a wave of sodium light, that is a light like that marked " $D$ " on the spectrum, a light produced by a spirit lamp with salt in it. The sodium vapour is heated up to several thousand degrees, when it becomes self Juminous and gives such a light as we get by throwing salt upon a spirit lamp in the game of snapdragon.

I hold in my hand a beautiful grating of glass silvered by Liebig's process with metallic silver, a grating with 6480 lines to the inch, belonging to my friend Prof. Barker, which he has kindly brought here for us this evening. You will see the brilliancy of colour as I turn the light reflected from the grating toward you, and pass the beam round the room. You have now seen directly with your own eyes these brilliant colours reflecter from the grating, and you have also seen them thrown upon the screen from a grating placed in the lantern. With a grating of 1 7,000 lines-a much greater number of lines per inch than the other-you will see how much further from the central bright space the first spectrum is; how much more this grating changes the direction or diffraction of the beam of light. Here is the centre of the grating, and there is the first spectrum. You will note that the violet light is least diffracted and the red light is most diffracted. This diffraction of light first proved to us definitely the reality of the undulatory theory of light.

You ask why does not light go round a corner as sound does. Light does go round a corner in these diffraction spectra; it is shown going round a corner, it passes through these bars and is turned round an angle of $30^{\circ}$. Light going round a corner by instruments adapted to show the result, and to measure the angles at which it is turned, is called the diffraction of light.

I can show you an instrument which will measure the wave lengths of light. Without proving the formula, let me tell it to you. A spirit lamp with salt sprinkled on the wick gives very nearly homogeneous light, that is to say, light all of one wave length, or all of the same period. I have a little grating which I take in my hand. I look through this grating and see that

${ }^{3}$ Showing the chromatic bands thrown upon the screen from a diffraction grating. 
candle before me. Close behind it you see a blackened slip of wood with two white marks on it ten inches asunder. The line on which they are marked is placed perpendicular to the line at which I shall go from it. When I look at this salted spirit lamp I see a series of spectra of yellow light. As I am somewhat short-sighted I am making my eye see with this eyeglass and the natural lenses of the eye what a long-sighted person would make out without an eyeglass. On that screen you saw a succession of spectra. I now look direct at the candle and what do I see? I see a succession of five or six brilliantly coloured spectra on each side of the cardle. But when I look at the salted spirit lamp, now I see ten spectra on one side and ten on the other, each of which is a monochromatic band of light.

I will measure the wave lengths of light thus. I walk away to a considerable distance and look at the candle and marks. see a set of spectra. The first white line is exactly behind the candle. I want the first spectrum to the right of that white line to fall exactly on the other white line, which is ten inches from the first. As I walk away from it I see it is now very near it ; it is now on it. Now the distance from ny eye is to be measured, and the problem is again to reduce feet to inches. The distance from the spectrum of the flame to my eye is thirty-four feet nine inches. Mr. President, how many inches is that? $4 \mathrm{I} 7$ inches, in round numbers 420 inches. Then we have the proportion, as 420 is to Io so is the length from bar to bar of the grating to the wave length of sodium light. That is to say, as forty-two is to one. The distance from bar to bar is the four-hundredth of a centimetre: therefore the forty-second part of the fourhundredth of a centimetre is the required wave length, or the I6,80oth of a centimetre is the wave length according to our simple, and easy, and hasty experiment. The true wave length of sodium light, according to the most accurate measurement, is about a 17,000 th of a centimetre, which differs by scarcely more than I per cent. from our result !

The only apparattus you see is this little grating; it is a piece of glass with four-tenths of an inch ruled with 400 fine lines. Any of you who will take the trouble to buy one may measure the wave lengths of a candle flame himself. I hope some of you will be induced to make the experiment for yourselves.

If I put salt on the flame of a spirit lamp, what do I see through this grating? I see merely a sharply defined yellow light, constituting the spectrum of vaporised sodium, while from the candle flame I see an exquisitely coloured spectrum, far more beautiful than I showed you on the screen. I see in fact a series of spectrums on the two sides with the blue toward the candle flame, and the red further out. I cannot get one definite thing to measure from in the spectrum from the candle flame as I can with the flame of a spirit lamp with the salt thrown on it, which gives, as I have said, a simple yellow light. The highest blue light I see in the candle flame is now exactly on the line. Now measure to my eye, it is forty-four feet four inches, or 532 inches. The length of this wave then is the 532 nd part of the four-hundredth of a centimetre, which would be the $2 \mathrm{I}, 28$ oth of a centimetre, say the $2 \mathrm{I}, 000$ th of a centimetre. Then measure for the red, and you would find something like the I I, oooth for the lowest of the red light.

Lastly, how do we know the frequency of vibration?

Why, by the velocity of light. How do we know that? We know it in a number of different ways, which I cannot explain now, because time forbids. Take the velocity of light. It is 187,000 British statute miles per second. But it is much better to take a kilometre for the unit. That is about six-tenths of a mile. The velocity is very accurately 300,000 kilometres per second; that is, 30,000,000,000 centimetres per second. Take the wave length as the 17 ,ocoth of a centimetre, and you find the frequency of the sodium light to be 5 ro million million per second. There, then, you find a calculation of the fre-

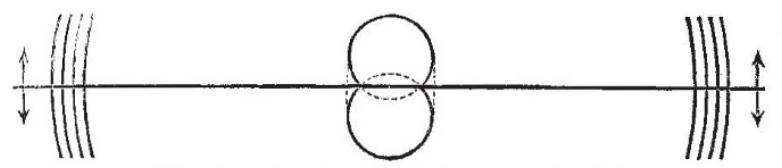

Vibrating spherule embedded in an elastic solid.

quency from a simple observation which you can all make for yourselves.

Lastly, I must tell you about the colour of the blue sky which was illustrated by the spherule embedded in an elastic solid. I want to explain to you in two minutes the mode of vibrations.
Take the simplest plane polarised light. Here is a spherule which is producing it in an elastic solid. Imagine the solid to extend miles horizontally and miles down, and imagine this spherule to vibrate up and down. It is quite clear that it will make transverse vibrations similarly in all horizontal directions. The plane of polarisation is defined as a plane perpendicular to the line of vibration. Thus, light produced by a molecule vibrating up and down, as this red globe in the jelly before you, is polarised in a horizontal plane, because the vibrations are vertical.

Here is another mode of vibrations. Let me twist this spherule in the jelly as I am doing it, and that will produce vibrations, also spreading out equally in all horizontal directions. When I twist this globe round, it draws the jelly round with it; twist it rapidly back, and the jelly flies back. By the inertia of the jelly the vibrations spread in all directions, and the lines of vibration are horizontal all through the jelly. Everywhere, miles away, that solid is placed in vibration. You do not see it, but you must understand that they are there. If it flies back it makes vibration, and we have waves of horizontal vibrations travelling out in all directions from the exciting molecule.

I am now causing the red globe to vibrate to and fro horizontally. That will cause vibrations to be produced which will be parallel to the line of motion at all places of the plane perpendicular to the range of the exciting molecule. What makes the blue sky? These are exactly the motions that make the blue light of the sky, which is due to spherules in the luminiferous ether, but little modified by the air. Think of the sun near the horizon; think of the light of the sun streaming through and giving you the azure blue and violet overhead. Think first of any one particle of the sun, and think of it moving in such a way as to give horizontal and vertical vibrations and what not of circular and elliptic vibrations.

You see the blue sky in high-pressure steam blown into the air ; you see it in the experiment of Tyndall's blue sky, in which a delicate condensation of vapour gives rise to exactly the azure blue of the sky.

Now the motion of the luminiferous ether relatively to the spherule gives rise to the same effect as would an opposite motion impressed upon the spherule quite independently by an independent force. So you may think of the blue colour coming from the sky as being produced by to-and-fro vibrations of matter in the air, which vibrates much as this little globe vibrates embedded in the jelly.

The result in a general way is this : The light coming from the blue sky is polarised in a plane through the sun, but the blue light of the sky is complicated by a great number of circumstances, and one of them is this, that the air is illuminated not only by the sun but by the earth. If we could get the earth covered by a black cloth, then we could study the polarised light of the sky with simplicity, which we cannot do now. There are, in Nature, reflections from seas and rocks and hills and waters in an indefinitely complicated manner.

Let observers observe the blue sky not only in winter when the earth is covered with snow, but in summer when it is covered with dark green foliage. This will help to unravel the complicated phenomena in question. But the azure blue of the sky is light produced by the reaction on the vibrating ether of little spherules of water, of perhaps a fifty-thousandth or a hundred-thousandth of a centimetre diameter, or perhaps little motes, or lumps, or crystals of common salt, or particles of dust, or germs of vegetable or animal species wafted about in the air. Now what is the luminiferous ether? It is matter prodigionsly less dense than air-millions and millions and millions of times less dense than air. We can form some sort of idea of its limitations. We believe it is a real thing, with great rigidity in comparison with its density, and it may be made to vibrate 400 million million times per second and yet with such rigidity as not to produce the slightest resistance to any body going through it.

Going back to the illustration of the shoemaker's wax : if a cork will in the course of a year push its way up through a plate of that wax when placed under water, and if a lead bullet will penetrate downwards to the bottom, what is the law of the resistance? It clearly depends on time. The cork slowly in the course of a year works its way up through two inches of that substance give it one or two thousand years to do it and the resistance will be enormously less; thus the motion of a cork or bullet, at the rate of one inch in 2000 years, may be compared with that of the earth, moving at the rate of six times ninety-three million miles a year, or nineteen miles per second, through the lumi- 
niferous ether ; but when we have a thing elastic like jelly and yielding like pitch, surely we have a large and solid ground for our faith in the speculative hypothesis of an clastic luminiferous ether, which constitutes the wave theory of light.

\section{SCIENTIFIC SERTALS}

Bulletin de la Société de Géographie, Paris, 3 Trimestre, 1884. -The principal portion of this number is occupied by papers of M. Huber, who spent the years 1878 to 1882 in Arabia on a scientific mission on behalf of the Department of T'ublic Instruction. In the first he introduces $\mathbf{I} 45$ inscriptions which he found in various parts of Central Arabia on rocks. The second article is the first instalment (accompanied by a map) of an account of his numerous and extensive journeys in the same region, from Palmyra and Bagdad in the north, to Kheiber in the south. A glance at the route map shows that he has explored the greater part of this region during his prolonged stay there. - M. Petitin, in his account of his journey in Indo-China, gives a lengthy description of the difficulties and dangers which the traveller encounters in this peninsula. He was selected by Admiral de la Grandière when Governor of Saigon to make a geological investigation of Cochin-China, Siam, Hainan, and Formosa, but the death of the governor and the appointment of another whose views were different cut M. Petitin's explorations short. He saw enough, however, to give a brief account of the geology of Cochin-China, and to give the intending traveller much advice as to his arrangements and preparations. He also urges his countrymen to extend their dominion in the Indo-Chinese peninsula, especially in Tonquin, where the Red River affords them an opening into the heart of China.-M. la Mes1le's paper on the eastern provinces of Australia is little more than a lively account of a journey in Queensland, while the object of $\mathrm{M}$. Simonin's articlc on the ports of Great Britain-especially London, Liverpool, and Glasgow--is not quite apparent, unless it be to urge his countrymen to go and do likewise with their ports.

Verhandlungen der Gesellschaft fïr Erakunde su Berlin, Band xi., Nos. 6 and 7.-Herr Muiller-Beeck, in the trade of Further India deals largely with trade routes into the Shan States and China. The Songkoi route into Yunnan he regards as one of great difficulty on account of the rapids. The delta also is constantly extending. IIanoi is now Iro miles from the sea; in the seventeenth contury it was only half that distance. For half the year the upper part of the river is only navigable for boats of four tons, and when Manhao is reached, there is still a difficult land journey to Yunnan. The population also, he thinks, will form a grave obstacle to any regular trade by this channel.-Herr Buchta, in the Soudan and the Mahdi, deals purely with the political side of the Soudan question.Prof. Seelstrang gives much interesting geographical and statistical information about the province of Santa Fé, in the Argentine Republic. - The usual notices of other societies and of new books conclude the number.

\section{SOCIETIES AND ACADEMIES} LONDON

Linnean Society, November 20.-Prof. P. Martin Duncan, F.R.S., Vicc-President, in the chair.-Mr. A. Roope Hunt was elcted a Fellow.-Mr. F. B. Forbes drew attention to specimens of pods and seeds used by the Chinese in place of soap. He stated that for ordinary detergent purposes an impure earthy soda and a lye made from ashes are employed. The leaves of Hibiscus syriacus and Ginko biloha are occasionally used for cleansing the head. The most favourite substance, however, is the fruit of certain Leguminos $x$ (Fei-tsao-tow). The late Daniel Hanbury figures these seeds as a species of Dialium. Dr. Porter Smith says they are the product of the Acacia concinna (Mimosa saponaria, Roxb.). Dr. Brcitschneider asscrts, on the contrary, that they belong to Gymnoclatus chinensis, originally described by Baillon from pods only. Specimens at Kew lately figured in the "Icones Plantarum," are young leaves, fruit, and flowers from Foochow ; those now exhibited (by Mr. Forbes) are, however, much finer examples from Ningpo and Wahu. The pods are roasted and kneaded into small balls used for washing clothes, and the head in bathing, but, on account of their unpleasant smell, they are prohibited in the public haths. The pods of Gleditschia sinensis, Lamk. (Tsao-chio) are used for the same pur- poses as Gymnocladus, those shown at the meeting being from Pekin and Shanghai district. One appears to answer to Dr. Hance's new $G$. aylocarpa. Bentham refers a South China trec to $G$. sinensis. Lamarck founded his species on a tree growing in the Jardin des Plantes, raiserl from sceds sent by Père Incarville 200 years ago from Pekin. It is doubtful if the northern and southern plants are identical. The pods are broken into small bits soaked in boiling water until an oily substance is floated, when they are ready for use. Another saponaceous substance is derived from Sapindus makarosi (the $S$. chinensis or Kolveteria poniculata, Lam.), specimens of which were shown from Ningpo. - Messrs. H. and T. Groves exhibited specimens of (I) Chara connivens, collected at Slapton, South Devon, the only known British station, for no trace of the plant is now to be found at Stokes Bay; (2) Chara canescens, obtained from a pool between Helston and the Lizard, West Cornwall, by Messrs. Guardia and Groves, and also at Little Sea, Studland, Dorset, by Mr. Mansell Pleydell.--Mr. Geo. Murray showerl dried and moistened examples of an Algæe, Gloxocapsa, found by Mr. Pryer in hirds'-nest caves in North Borneo.-Mr. J. G. Baker read the following letter from Mr. W. Brockhurst, of Didsbury, dated November 17, 1884:--"On April 2 I had the pleasure of exhibiting to the Society a number of preparec specimens of the daffodil, which appeared to prove that double daffodil flowers might produce seeds, and I advanced some arguments, based upon the observations I had made, to show that they were spread over wide areas in a wild state of seeding. The specimens showed the seed-vessels filled with ovules, but this did not fully prove that ripe sceds capable of germination would be matured. I therefore carefully observed a number of flowers of double daffodils (Narcissus telamoncus-plenus), and marked them as they went out of bloom, to prevent any mistakes. One of these produced a capsule containing nine shining black seeds, which were gathered on June 24 , and at once sowed in a pot, and covered with a sheet of glass. Of these seeds four have already germinated, and show grass-like growths an inch above the soil. This therefore complctes the proof."-Mr. W. T. Thiselton Dyer pointed out and made remarks on some sterile runners of Mentha fiperita, and the remains of flowers of Epilobium hirsutum, both taken from a wreath found by Prof. Maspero in a tomb near Thebes, and supposed to be of the zoth or 26th dynasty; Mr. Dyer also exhibited fresh flowers of Ipomea purpureo-crerulea. - $\mathrm{Mr}$. Thos. Christy exhibited two specimens of Lycaste Skinneri, Lindl., one with two flowers on one stem, the other with an aborted lip adherent for the greater part of its length to the column. He also drew attention to samples of the tea (probably a species of Ilex) used largely in Bogota, but which is said to be deficient in flavour.-Mr. E. C. Stanford thereafter showed some of the products from seaweed, viz. :- Algin, the insoluble form of which (alginic acid) can be made into shirt-studs resembling horn, \&c.; the soluble algin (or alginate of soda), which diminishes the brittleness of shellac, besides other uses.-A paper was read by Mr. E. M. Holmes on Cinchona Ledgeriana as a species. The author expressed the opinion that under the name of $C$. Ledgcriana, a number of varieties or forms, and probably some hybrids of Cinchona Calisaya, are now under cultivation in the British colonies. He believer that, if more attention were paid to the characters afforded by the bark of trees, taken in conjunction with the other botanical characters of flower and fruit, these varieties and hybrids would be more easily defined and recognised. He considers that the plant published under the name of C. Ledgeriana by Dr. Trimen was probably referable to Weddell's Cinchona Calisaya, var. pallida, as a horticultural form, for which the author proposed the name "Trimeniana." - A paper was read, notes on the habits of some Australian Hymenopterous Aculeata, by II. L. Roth. Hc states that the wasps of the genus Pelopaus (P. latus) build their nests on the walls, ceilings, legs of chairs, under the table, in cupboards, vases, between pictures and the walls, on curtains, in all sorts of crevices in the house, and on the roof. No place is safe from their intrusion. When a cell is completed, the wasp goes in search of spicters, and, scizing these, packs their half dead bodics in the cell, lays an egg, and closes the cell-top; thereafter rows of cells are added to the primary one and dealt with in the same fashion, generally finishing with a streaked coating of mud, thus to deceive as to the real contents beneath. These wasps are infested with Dipterous parasites. Of the Australian ants, Formica minigro is numerous, bold, and destructive. They destroy the web of certain caterpillars and wriggle them out, when they fall a prey to a host of attendant 